\title{
Critical Success Factors for ERP Projects in Small and Medium-sized Enterprises - The Perspective of Selected German SMEs
}

\author{
Christian Leyh \\ Technische Universität Dresden \\ Chair of Information Systems, esp. IS in Manufacturing \\ and Commerce \\ Helmholtzstr. 10, 01069 Dresden, Germany \\ Email: Christian.Leyh@tu-dresden.de
}

\begin{abstract}
The aim of our study was to provide a contribution to the research field of the critical success factors (CSFs) of ERP projects, with a specific focus on smaller enterprises (SMEs). Therefore, we conducted a systematic literature review in order to update the existing reviews of CSFs. On the basis of that review, we led several interviews within German SMEs that have implemented ERP systems. As a result, we showed that all factors found in the literature also affected the success of ERP projects in SMEs. However, within those projects, technological factors gained much more importance compared to those factors that most influence the success of larger ERP projects. For SMEs, factors such as the Organizational fit of the ERP system as well as ERP system tests are even more important than Top management support or Project management, which were the most important factors for large-scale companies.
\end{abstract}

\section{INTRODUCTION}

$\mathrm{T}$ ODAY'S enterprises are faced with the globalization of markets and rapidly changing economies. In order to cope with these fluid conditions, the use of technology, as well as information and communication systems, is almost mandatory. Specifically, the adoption of enterprise resource planning (ERP) systems as standardized systems that encompass the activities of entire enterprises has become an important factor for today's businesses. The demand for ERP applications has increased for several reasons, including competitive pressure to become low-cost producers, expectations of revenue growth, and the desire to re-engineer businesses to respond to market challenges. A properly selected and implemented ERP system offers several benefits including considerable reductions in inventory costs, raw material costs, lead time for customers, production time, and production [1]-[4]. Therefore, the majority of enterprises around the world now use ERP systems. For example, according to a survey conducted in Germany from 2010 to 2011, ERP systems are used in more than 92 percent of all German industrial enterprises [5].

Due to the saturation of ERP markets targeting large-scale enterprises, ERP system manufacturers today are also concentrating on the growing market of small and mediumsized enterprises (SMEs) [3], [6]. This has resulted in a highly fragmented ERP market and a great diffusion of ERP systems throughout enterprises in nearly every industry and of every size [7]-[9]. Due to the strong demand and the high fragmentation of the market, there are many ERP systems with different technologies and philosophies currently available on the market. This multitude of software manufacturers, vendors, and systems implies that enterprises that use or want to use ERP systems must strive to find the "right" software as well as to be aware of the factors that influence the success of the implementation project.

The implementation of an information system (e.g., an ERP system) is a complex and time-consuming project, and in the process, companies face not only great opportunities but also enormous risks. To take advantage of potential opportunities without being affected by the risks of these implementation projects, it is essential to focus on those factors that support the successful implementation of an information system [10], [11]. Being aware of these factors, a company can positively influence the success of the implementation project and effectively minimize the project's risks [10]. Recalling these so-called critical success factors (CSFs) is of high importance whenever a new system is to be adopted and implemented or a current system needs to be upgraded or replaced. Errors during the selection, implementation, or maintenance of ERP systems, incorrect implementation approaches, and ERP systems that do not fit the requirements of the enterprise can all cause financial disadvantages or disasters, perhaps even leading to insolvencies. Several examples of such negative scenarios can be found in the literature (e.g., [12], [13]). SMEs must be especially aware of CSFs, since they lack the financial, material, and personnel resources of larger companies. Thus, they are under greater pressure to implement and run ERP systems without failure and as smoothly as possible.

These critical success factors have already been considered in numerous scientific publications. Several case studies, surveys, and literature reviews have previously been conducted by different researchers (e.g., [4], [14]-[16]). However, the existing ERP system success-factor research has focused mostly on the selection and implementation of ERP systems in large enterprises. Less attention has been paid to implementation projects in SMEs, despite the fact that research focusing on CSFs in smaller companies has been recommended by the research community for several years (e.g., [17], [18]).

Therefore, the aim of our study was to focus on the implementation of ERP systems in SMEs, focusing in 
particular on the differences in CSFs between larger ERP projects and smaller projects. Prior to this study, we conducted a systematic literature review in order to update the existing reviews of CSFs. On the basis of the CSFs identified, we conducted multiple interviews within German SMEs that have already implemented ERP systems in order to obtain insights into the similarities and differences in CSFs for ERP system implementation in SMEs. Overall, our study was driven by the following research question:

Q1: What similarities and differences exist between critical success factors for ERP implementation projects in larger and smaller enterprises?

Therefore, the paper is structured as follows. The next section gives a short overview of the subsequently discussed and important CSFs before the section that follows deals with the results of our literature review. Here, we will point out which factors are the most important and which factors seem to have little influence on the success of an ERP implementation project. Next, our data collection methodology is described before the results of the interviews are presented and the research question is answered. Finally, the paper concludes with a summary of the results and discusses the limitations of our study.

\section{CRITICAL SUCCESS FACTORS IDENTIFIED}

A CSF for ERP projects has been defined by [15] as a reference to any condition or element that was deemed necessary in order for the ERP implementation to be successful. To provide a comprehensive understanding of the different CSFs and their concepts, these are described in this section before presenting the research methodology and discussing the results. However, only the most-important and subsequently discussed factors are described. The detailed definitions of the other CSFs can be found in [7] and [19].

ERP system configuration: Since the initial ERP system version is based on best practices, a configuration or adaptation of the system according to business processes is necessary in every ERP implementation project. Hence, as closely as possible, the company should attempt to adopt the processes and options built into the ERP rather than seeking to modify the ERP [20]. Following [21], the more the original ERP software is modified (e.g., even beyond the "normal" configuration), the smaller the chance is for a successful implementation project. Hence, a clear business vision is helpful because it reduces the effort of capturing the functionality of the ERP business model and therefore minimizes the effort needed for the configuration [20]. Again, extensive system modifications will not only cause implementation problems but also interfere with system maintenance. Therefore, the need for fewer adjustments reduces the effort of integrating new versions, releases, or updates [22]

ERP system tests: In ERP implementation, "go live" on the system without adequate and planned system testing may lead to an organizational disaster. Tests and validation of an
ERP system are necessary to ensure that the system works correctly from a technical perspective, and that the business process configurations have been done the right way [23]. Therefore, testing and simulation exercises for both, the whole system and its separate parts and functions, have to be performed during and in the final stages of the implementation process [15], [24].

Organizational fit of the ERP system: The fact that the organizational fit of an ERP system should be examined and considered comprehensively before its implementation sounds logical. Nevertheless, ERP manufacturers often attempt to create blind confidence in their ERP packages, even if the organizational fit is obviously low. In [21], the extent to which the implementation success of an ERP system depends on the fit between the company and the ERP system was empirically examined, and it was found that the adaptation and configuration effort negatively correlate with implementation success. Therefore, the careful selection of an ERP system with consideration of its company-specific organizational fit, such as company size or industry sector, is essential, and appropriate ERP system selection is an important factor in the effort to ensure a good fit between the company and the ERP system.

Project management: Project management refers to the ongoing management of the implementation plan [15]. The implementation of an ERP system is a unique procedure that requires enterprise-wide project management. Therefore, it involves planning stages, the allocation of responsibilities, definitions of milestones and critical paths, training and human resource planning, and the determination of measures of success [25], [26]. This enables timely decisions and guarantees that such decisions are made by the "right" company members. Furthermore, continuous project management allows the focus to remain on the important aspects of ERP implementation and ensures that timelines and schedules are met [25]. Within project management, comprehensive documentation of the tasks, responsibilities, and goals is indispensable for the success of an ERP implementation [17].

Top management support and involvement: Top management support and involvement is one of the mostimportant success factors for ERP implementation [14]. Committed leadership at the top management level is the basis for the continuous accomplishment of every project [15]. Thus, innovations and, in particular, new technologies are more quickly accepted by employees if these innovations are promoted by top management. Before the project starts, top management has to identify the peculiarities and challenges of the planned ERP implementation. Since many decisions that must be made during the project can affect the whole enterprise, these decisions will require the acceptance and commitment of senior managers and often can only be made by them [27]. The commitment of top management is important for the allocation of necessary resources, for quick and effective decision making, for solutions to conflicts that need enterprise-wide acceptance, and for enlisting the cooperation of all departments [24]. 
User training: Missing or inadequate end user training is often a reason for failures in the implementation of new software. The main goal of end user training is to provide an effective understanding of the new business processes and applications as well as the new workflows that are created by the ERP implementation. Therefore, establishing a suitable plan for training employees is important [24]. Furthermore, during the implementation of such an extensive project, management must determine which employee is the best fit for which position or for which application of the new software. This depends strongly on the employee's previously acquired knowledge and/or additional training courses [28].

\section{LiterATURE REVIEW OF CRITICAL SUCCESS FACTORS}

In order to identify the factors that affect the success or failure of ERP projects, several case studies, surveys, and literature reviews have already been conducted by a number of researchers (e.g., [4], [15], [16], [20]-[22]).

However, most of the literature reviews cannot be reproduced because descriptions of the review methods and procedures are lacking. Some researchers have pointed out the limitations of literature review articles, noting specifically that they lack methodological rigor [29]. Therefore, in order to update the existing reviews by including current ERP literature, we conducted a literature review by systematically reviewing articles in five different databases as well as papers drawn from several international conference proceedings. More specifically, we conducted two separate literature reviews according to the same search procedure and steps. The first was performed in mid-2010 [7], [19]. Since we identified 20 or more papers published each year, it was essential for us to update this review every two or three years. Therefore, we conducted the second review in mid-2013. In the Appendix (see Tables 6 and 7) we provide an overview of the identified databases and conferences as well of the used search terms. The overall procedure for the literature review will not be part of this paper. It is described in detail in [7], [19], [30].

We identified 320 papers that referred to CSFs of ERP projects. These papers were reviewed again in depth in order to determine the various concepts associated with CSFs. For each paper, the CSFs were captured, along with the publication year, the type of data collection used, and the companies (i.e., the number and size) from which the CSFs were derived.

All 320 papers were published between 1998 and mid-2013. Table 1 shows the distribution of the papers by publication year. As is shown, most of the papers were published between 2006 and 2013.

Every year since 2004, approximately 20 papers about CSFs have been published, and since 2009, 30 or more papers a year have been published. Therefore, it can be argued that a review every two or three years is reasonable in order to update the results of previously performed literature reviews, especially when considering the rapidly evolving technology and changing system availability such
TABLE 1. PAPER Distribution BY YeAR

\begin{tabular}{|c|c|c|c|}
\hline Year & Papers & Year & Papers \\
\hline 2013 & 30 & 2005 & 15 \\
\hline 2012 & 31 & 2004 & 20 \\
\hline 2011 & 39 & 2003 & 11 \\
\hline 2010 & 37 & 2002 & 11 \\
\hline 2009 & 42 & 2001 & 5 \\
\hline 2008 & 22 & 2000 & 5 \\
\hline 2007 & 24 & 1999 & 3 \\
\hline 2006 & 24 & 1998 & 1 \\
\hline
\end{tabular}

as the concept of "Software-as-a-Service"-concept or ERP systems provided in the cloud.

Overall, 31 factors influencing the success of ERP system implementation were identified. Figure 1 shows the results of our review, i.e., the CSFs identified, their ranks, and each factor's total number of occurrences in the reviewed papers. The factors Top management support and involvement, Project management, and User training are the three mostnamed factors, with each being mentioned in more than 160 articles. The factor Top management support and involvement stands out; it is ranked \#1 and referred to in more than 200 papers. As mentioned above, we will not describe each factor and its concepts in detail in this paper. However, to provide a fuller understanding of the different CSFs and their concepts, we described all 31 factors in [19] and the top eight factors again in greater detail in [7].

Regarding the form of data collection, it must be stated that the papers consist of 144 single or multiple case studies, 118 surveys, and 58 literature reviews or articles where CSFs are derived from the chosen literature.

In most previous literature reviews, the CSFs were grouped without as much attention to detail; therefore, the number of CSFs used was lower (e.g., [4], [15]). However, we took a different approach in our review. For the 31 factors, we used a larger number of categories than other researchers because we expected the resulting distribution to offer more insight. If broader definitions for some CSFs might be needed at a later time, further aggregation of the categories is still possible. Comparing these results with other literature reviews (e.g., [15]), the top five factors are obviously similar, with only the ranked positions differing. Due to our large literature base, the total numbers of observed mentions are much higher. Therefore, the differences in the CSF frequencies are much higher as well, making the distinctions in the significance of the factors clearer. 


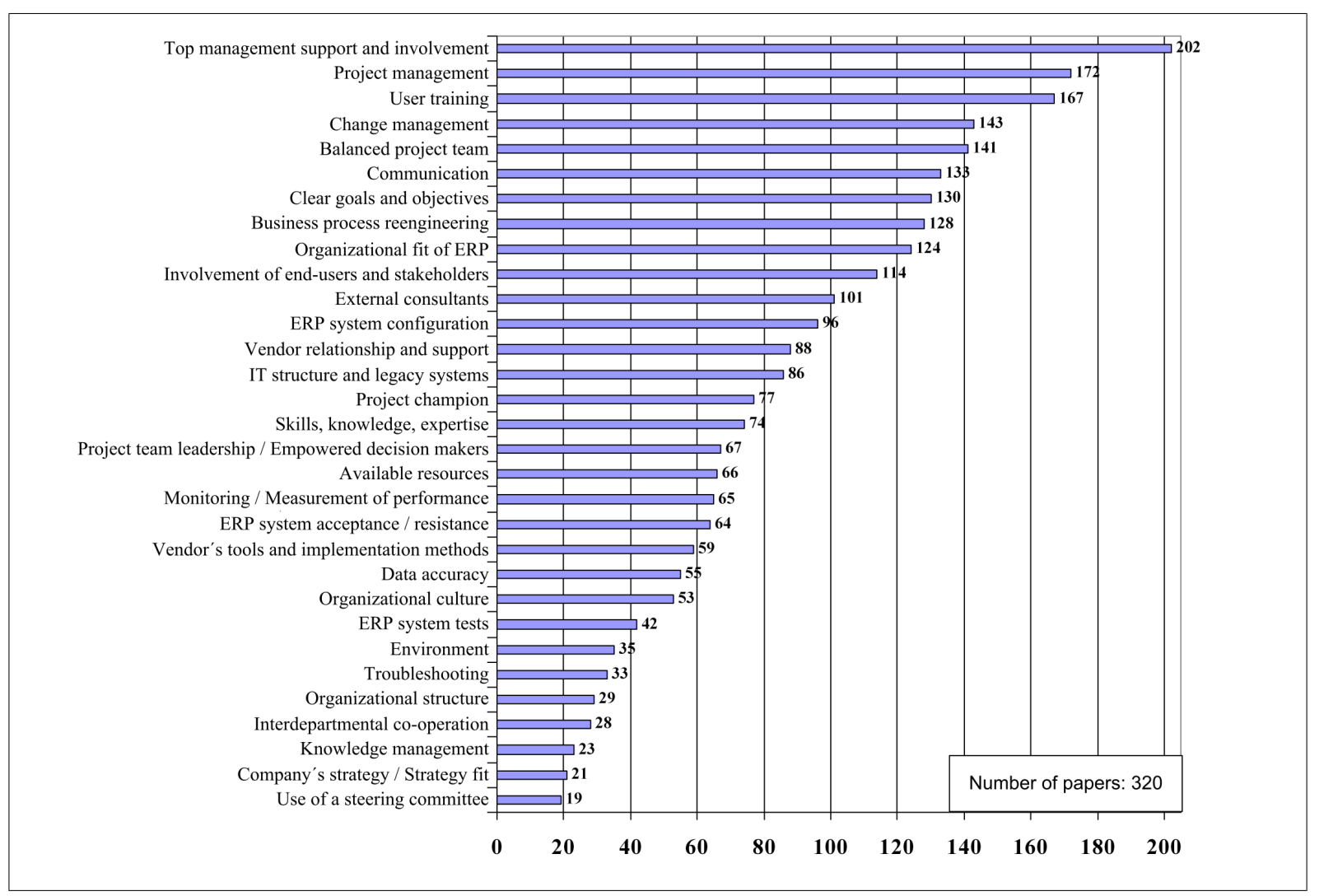

Figure 1. ERP Project CSFs in Rank Order Based on Frequency of Appearance in Analyzed Literature

Concerning company size during review 1 (conducted in mid-2010), only 12 papers explicitly focus on small and medium-sized enterprises (SMEs), mostly within single or multiple case studies. In the review update (conducted in mid-2013), 25 articles dealt with SMEs explicitly. In some surveys, SMEs are included and analyzed as well, but they are a minority in these surveys. Therefore, deriving CSFs that are important for SMEs is difficult and can be seen as still lacking in the CSF research.

Within these 37 papers focusing on SMEs, Top management support and involvement (mentioned in 25 articles), Project management (mentioned in 25 articles), and User training (mentioned in 22 articles) are again the most-frequently named factors for ERP projects in smaller enterprises. However, the differences in the CSF frequencies are only minimal and may be related to the small number of identified papers (see [30]). Therefore, deriving CSFs that are important for SMEs is difficult due to the small number of studies focusing solely on them. This is clearly a research gap in the research area of CSFs for ERP projects.

Therefore, our study focuses on this gap. We investigated these CSFs by interviewing SMEs that have implemented ERP systems. The results will be part of the following sections.

\section{CRITICAl Success Factors FOR SMEs’ ERP PROJECTS}

\section{Study Design - Data Collection Methodology}

To gain an understanding of the differences in the CSFs for ERP system projects in large-scale enterprises and SMEs, we used a qualitative exploratory approach within German small and medium-sized enterprises.

The units of analysis in our study are the implementation projects carried out within the SMEs. For the data collection, we conducted several interviews with members of the ERP implementation project teams, the department managers, or with the directors of the companies in order to identify the factors that they determined to be relevant for the success of their projects.

We interviewed employees of nine small and mediumsized enterprises located in Germany. The SMEs operate in different industry sectors and have implemented different ERP systems. Table 5 in the Appendix gives an overview of the companies and the interviewees.

Within these enterprises, there is a broad range of ERP systems (which cannot be named directly within this paper due to data protection). Only SME 1 and SME 3 have implemented the same ERP system; all other companies have implemented different systems. Some systems are quite small and industry specific and others are more widespread systems on the German ERP market. Most of the 
implementation projects took place within the mid-2000s. All of the interviewees (except one of the department managers from SME 2) were directly involved in the ERP system implementation projects.

To gain an in-depth and detailed view of the enterprises and their structures, we chose direct structured interviews as our method of data collection. The interviews were conducted in retrospect to the ERP projects between April and July 2013. The interviews were designed as partially standardized interviews using open to semi-open questions as initial starting points for the conversation. Both personal (face-to-face) interviews, as well as telephone interviews, were conducted by the author. An interview guideline was developed based on the questions of [31], who conducted a similar study, as well as on the basis of one of our previous CSF-studies that had another focus [32]. We changed the questions to align with our identified CSFs (see Figure 1) to ensure that all of the factors were discussed in the interviews. The interview guideline consisted of 52 main questions with further sub-questions that referred to the 31 identified CSFs. These questions were formulated in an open way so that it would be possible to identify "new" CSFs that were not results of the literature review. This questionnaire was sent to interviewees before the interviews took place to allow them to prepare for their interviews. The complete listing of the formulated questions and their assignment to the success factors will not be part of this paper but will be provided by the author upon request.

For a better analysis of the results, we recorded all interviews (the interviews typically took between 70 and 180 minutes) and transcribed them afterwards (resulting in about 200 pages of written text). As a first step, non-verbal and para-linguistic elements and other elements that were not relevant to the study were excluded. To evaluate the CSFs, the interviews were analyzed with reference to each CSF question block, and the statements of the interviewees were classified according to a three-tiered scale (2-very important factor; 1-important factor; 0-less/non-important factor) as well as for a finer classification according to a five-tiered scale (4-very important factor; 3-important factor; 2-factor was seen as relevant; 1-factor was mentioned but not seen as being very relevant; 0-factor was not seen as relevant or important/factor was not mentioned at all). We used these two scales to get a preliminary understanding of whether differences would occur by using a finer/more-detailed scale. Here, the five-tiered scale could be seen as more appropriate to quantify the importance of the factors mentioned during the interviews. Also, we

TABLE 2. CSFs ACCORDING THE FIVE-TIER-ScAle RATING

\begin{tabular}{|c|c|c|c|c|c|}
\hline Rank & Factor & $\begin{array}{c}\text { Factor rating } \\
\text { (five-tier- } \\
\text { scale) }\end{array}$ & Rank & Factor & $\begin{array}{l}\text { Factor rating } \\
\text { (five-tier-scale) }\end{array}$ \\
\hline 1 & User training & 33 & 18 & ERP system acceptance / resistance & 16 \\
\hline 2 & ERP system tests & 32 & \multirow[b]{2}{*}{19} & Change management & 14 \\
\hline 3 & $\begin{array}{l}\text { Organizational fit of the ERP } \\
\text { system }\end{array}$ & 31 & & IT structure and legacy systems & 14 \\
\hline 4 & Clear goals and objectives & 30 & \multirow{3}{*}{21} & Troubleshooting & 12 \\
\hline 5 & ERP system configuration & 28 & & Organizational structure & 12 \\
\hline 6 & $\begin{array}{l}\text { Top management support and } \\
\text { involvement }\end{array}$ & 27 & & Data accuracy & 12 \\
\hline 7 & $\begin{array}{l}\text { Project team leadership / } \\
\text { empowered decision makers }\end{array}$ & 26 & \multirow{2}{*}{24} & Knowledge management & 11 \\
\hline 8 & Balanced project team & 24 & & $\begin{array}{l}\text { Monitoring and performance } \\
\text { measurement }\end{array}$ & 11 \\
\hline \multirow{3}{*}{9} & Communication & 23 & 26 & Project champion & 10 \\
\hline & $\begin{array}{l}\text { Involvement of end-users and } \\
\text { stakeholders }\end{array}$ & 23 & \multirow{3}{*}{27} & Environment & 6 \\
\hline & Company's strategy / strategy fit & 23 & & Organizational culture & 6 \\
\hline \multirow{2}{*}{12} & Available resources & 21 & & Interdepartmental cooperation & 6 \\
\hline & External consultants & 21 & 30 & Use of a steering committee & 5 \\
\hline \multirow[t]{2}{*}{14} & Business process reengineering & 19 & 31 & $\begin{array}{l}\text { Vendor's tools and implementation } \\
\text { methods }\end{array}$ & 4 \\
\hline & Vendor relationship and support & 19 & & & \\
\hline \multirow{2}{*}{16} & Project management & 17 & & & \\
\hline & Skills, knowledge, and expertise & 17 & & & \\
\hline
\end{tabular}


TABLE 3. COMPARISON OF THE TOP FIVE FACTORS

\begin{tabular}{|c|l|l|l|}
\hline Rank & $\begin{array}{c}\text { Results of the literature review (all } \\
\text { company sizes) }\end{array}$ & \multicolumn{1}{|c|}{$\begin{array}{c}\text { Results of the literature review } \\
\text { (only SMEs (see [22])) }\end{array}$} & Factors from the interviews \\
\hline 1 & $\begin{array}{l}\text { Top management support and } \\
\text { involvement }\end{array}$ & $\begin{array}{l}\text { Top management support and } \\
\text { involvement }\end{array}$ & User training \\
\hline 2 & Project management & Project management & ERP system tests \\
\hline 3 & User training & User training & Organizational fit of the ERP system \\
\hline 4 & Change management & Balanced project team & ERP system configuration \\
\cline { 2 - 3 } & Change management & & \\
\hline 5 & Balanced project team & &
\end{tabular}

TABle 4. CATEgorization of CSFs (Model AdAPTED From ([20], [33], [34])

\begin{tabular}{|c|c|c|c|c|}
\hline & \multicolumn{2}{|l|}{ Strategic } & \multicolumn{2}{|l|}{ Tactical } \\
\hline \multirow{18}{*}{ 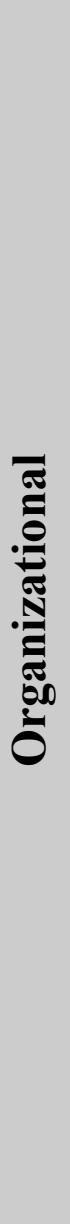 } & Critical Success Factors & Rank & Critical Success Factors & Rank \\
\hline & Clear goals and objectives & 4 & User training & 1 \\
\hline & Top management support and involvement & 6 & Communication & 9 \\
\hline & $\begin{array}{l}\text { Project team leadership / Empowered } \\
\text { decision makers }\end{array}$ & 7 & External consultants & 12 \\
\hline & Balanced project team & 8 & Project management & 16 \\
\hline & Involvement of end-users and stakeholders & 9 & Skills, knowledge and expertise & 16 \\
\hline & Company's strategy / Strategy fit & 9 & Troubleshooting & 21 \\
\hline & Available resources & 12 & Monitoring / Measurement of performance & 24 \\
\hline & Business process reengineering & 14 & Interdepartmental cooperation & 27 \\
\hline & Vendor relationship and support & 14 & & \\
\hline & ERP system acceptance / resistance & 18 & & \\
\hline & Change management & 19 & & \\
\hline & Organizational structure & 21 & & \\
\hline & Knowledge management & 24 & & \\
\hline & Project champion & 26 & & \\
\hline & Organizational culture & 27 & & \\
\hline & Environment & 27 & & \\
\hline & Use of a steering committee & 30 & & \\
\hline$\vec{\pi}$ & Organizational fit of the ERP system & 3 & ERP system tests & 2 \\
\hline bo & ERP system configuration & 5 & IT structure and legacy systems & 19 \\
\hline 를 & & & Data accuracy & 21 \\
\hline 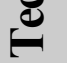 & & & Vendor's tools and implementation methods & 31 \\
\hline
\end{tabular}


discussed the factor rating with other researchers in this field to reduce the subjectivity of the rating.

\section{Results of the Interviews}

For each interview, a ranking of the critical success factors was set up by the author. A final ranking was created including all interviews and all individual rankings (see Table 2). As shown, the three most-important factors for ERP implementation projects in small and medium-sized companies according to our study are User training, ERP system tests, and Organizational fit of the ERP system with more than 30 out of a possible 36 points. Also, no further factors could be identified during the interviews. Each of the 31 factors stemming from the literature review was mentioned by at least one interviewee.

With the exception of User training, neither of the two other factors were part of the top five, within the ranking of the literature review (see Table 3). The factor ERP system tests was not even part of the top 20 in the literature review (see Figure 1). In addition, Organizational fit of the ERP system has gained more importance, according to our interviewees. The importance of both factors indicates that SMEs are forced to find the right ERP system that fits their needs and to test the system properly before the Go-Live. As mentioned in the first section, due to their lack of financial, material, and personnel resources compared to larger companies, failures during and/or after the Go-Live in SMEs can easily cause financial disadvantages or disasters, perhaps even leading to the insolvency of such small companies.

This is supported by the importance of the top two factors in our study. Reasons for this can be seen in the highly fragmented ERP system market as well as in the increasing multitude of software manufacturers and ERP systems. Enterprises are facing increasingly greater difficulties in identifying the best-fitting ERP system. Therefore, more emphasis is placed upon the selection of the "right" ERP system with a high Organizational fit of the ERP system. Together with selecting the right software, customizing the ERP system is also seen as an important factor for ERP projects in SMEs. The factor ERP system configuration is ranked at $\# 5$ in the interviews, whereas this factor was not part of the top 10 within the literature review. This also supports the statement that SMEs strongly depend on ERP systems that fit their needs, even more so than large companies do. SMEs cannot afford to be restricted by stiff ERP processes; moreover, it is important that the system is adapted according to the SME's own business processes.

To categorize critical success factors, in [20] a matrix scheme is suggested. Here, the authors consider the tactical or strategic direction of the CSFs and divide them into organizational and technological factors. Thus, tactical CSFs relate to short-term aspects and goals of the system implementation project itself, whereas strategic factors aim towards long-term impacts of activities with strong connections to the development of the organization in relation to mission, vision, and core competencies of the business activity. Considering the technological and organizational character of the CSFs, the specificity and significance of technological factors are strongly dependent on the ERP systems themselves, whereas organizational factors focus on corporate culture and its environment, with its specific processes and structures [20], [33], [34].

Table 4 gives an overview of the categorization of the identified CSFs in our study with a focus on their ranking. We oriented the classification and categorization of the factors according to [33] and [34]. The top 10 factors are highlighted.

It can be seen that only a few CSFs (six out of 31) are technological factors, whereas more than 50 percent of the factors (17 out of 31) are organizational factors with a strategic characteristic. However, the top 10 factors are spread out among all four categories, although most of them are part of the organizational category. Remarkably, two of the top three factors are part of the technological view. This supports the statement above that the technological aspects of ERP projects and their impacts on enterprises are considered more important for SMEs than for larger companies. However, smaller enterprises and ERP manufacturers should consider both the organizational and technological aspects when implementing an ERP system.

\section{V.CONCLUSION AND LIMITATIONS}

The aim of our study was to gain insight in the research field of CSFs for ERP implementation projects, with a focus on ERP projects in small and medium-sized enterprises. Research in the field of ERP system projects and their CSFs provides valuable information that may enhance the degree to which an organization's implementation project succeeds [15]. As a first step, we carried out a systematic literature review to identify CSFs and to update existing reviews. Our review found a variety of papers, i.e., case studies, surveys, and literature reviews, focusing on CSFs. All in all, we identified 320 relevant papers dealing with CSFs of ERP system projects. From these existing studies, we derived 31 different CSFs (see Figure 1). Most of the identified papers and studies focus on large companies. Small and mediumsized enterprises are - if included at all - usually underrepresented in quantitative studies. Studies exclusively focusing on SMEs are rare. We identified 37 of the 320 articles with this explicit focus. These represent only 12 percent of all published papers with a focus on CSFs. Even though research focusing on CSFs in smaller companies has been recommended by the research community for several years (e.g., [17], [18]), our reviews reveal that SMEs are still not the primary focus of CSF research. Therefore, this still can be seen as a clear lack of research.

To address this concern, we developed a study with a specific SME focus. We conducted several interviews within SMEs that have implemented ERP systems. Using a guideline consisting of 52 initial questions about CSFs, we conducted nine interviews. We found that all 31 factors found in the literature review were mentioned by at least one interviewee, and therefore, all 31 factors also in some way affect the success of the ERP system projects in SMEs. However, contrary to the ranking resulting from the literature review, we identified factors with a more- 
technological focus as being important for those ERP projects. Here, the factors ERP system tests and Organizational fit of the ERP system as well as ERP system configuration as part of the top five factors refer to more technological aspects. Hence, factors with an organizational characteristic could also be identified as part of the top five factors in our study (User training, Clear goals and objectives). For the interviewees, User Training is seen as the most important factor influencing the success of ERP implementation projects.

Regarding the research question, our study was able to show that all factors that influence the success of ERP system implementation projects in large-scale enterprises also influence ERP projects in SMEs. We could not identify any additional factors that were not already referred to in the literature. However, we could show that the importance of the factors differs a lot and that SMEs and also the ERP manufacturers have to be aware of these differences in the factors' characteristics, focusing also on technological aspects of the ERP implementations rather than focusing mainly on the organizational factors, as they are more important for large-scale companies.

A few limitations of our study must be mentioned as well. For our literature review, we are aware that we cannot be certain that we have identified all relevant papers published in journals and conferences, since we made a specific selection of five databases and five international conferences (see Tables 6 and 7 in the Appendix). Therefore, journals not included in our databases and the proceedings from other conferences might also provide relevant articles. Another limitation is the coding of the CSFs. We attempted to reduce any subjectivity by formulating coding rules and by discussing the coding of the CSFs with several independent researchers. However, other researchers may code the CSFs in other ways. For the interview study, the interviews conducted and data evaluated represent only an investigation of sample ERP projects in SMEs. These results are limited to the specifics of these enterprises. In light of this, we will conduct further case studies and several larger surveys to broaden the results of this investigation.

\section{REFERENCES}

[1] T.H. Davenport, Mission critical: realizing the promise of enterprise systems. Boston, USA: Harvard Business School Press, 2000, DOI: $10.1225 / 9067$.

[2] S.V. Grabski, and S.A. Leech, "Complementary controls and ERP implementation success," International Journal of Accounting Information Systems, vol. 8, no. 1, pp. 17-39, 2007, DOI: 10.1016/j.accinf.2006.12.002.

[3] S.C.L. Koh, and M. Simpson, "Change and uncertainty in SME manufacturing environments using ERP," Journal of Manufacturing Technology Management, vol. 16, no. 6, pp. 629-653, 2005, DOI 10.1108/17410380510609483

[4] T.M. Somers, and K. Nelson, "The impact of critical success factor across the stages of enterprise resource planning implementations," in Proceedings of the 34th Hawaii International Conference on System Sciences (HICSS 2001), Hawaii, USA, 2001, DOI: 10.1109/HICSS.2001.927129.

[5] Konradin $\mathrm{GmbH}$, Konradin ERP-Studie 2011: Einsatz von ERP Lösungen in der Industrie. Leinfelden-Echterdingen, Germany: Konradin Mediengruppe, 2011.

[6] A. Deep, P. Guttridge, S. Dani, and N. Burns, "Investigating factor affecting ERP selection in the made-to-order SME sector," Journal of
Manufacturing Technology Management, vol. 19, no. 4, pp. 430-446, 2008, DOI: $10.1108 / 17410380810869905$.

[7] C. Leyh, "Critical Success Factors for ERP System Implementation Projects: A Literature Review," in Advances in Enterprise Information Systems II, C. Møller, and S. Chaudhry, Eds. Leiden, The Netherlands: CRC Press/Balkema, 2012, pp. 45-56.

[8] A. Winkelmann, and K. Klose, "Experiences while selecting, adapting and implementing ERP systems in SMEs: a case study," in Proceedings of the 14th Americas Conference on Information Systems (AMCIS 2008), Toronto, Ontario, Canada, 2008.

[9] A. Winkelmann, and C. Leyh, "Teaching ERP systems: A multiperspective view on the ERP system market," Journal of Information Systems Education, vol. 21, no. 2, pp. 233-240, 2010.

[10] A. Jones, J. Robinson, B. O'Toole, and D. Webb, "Implementing a bespoke supply chain management system to deliver tangible benefits," International Journal of Advanced Manufacturing Technology, vol. 30, no. 9/10, pp. 927-937, 2006, DOI: 10.1007/s00170-005-0065-2.

[11] E.W.T. Ngai, T.C.E. Cheng, and S.S.M. Ho, "Critical success factors of web-based supply-chain management systems: an exploratory study," Production Planning \& Control, vol. 15, no. 6, pp. 622-630, 2004, DOI: 10.1080/09537280412331283928.

[12] T. Barker, and M.N. Frolick, "ERP Implementation Failure: A Case Study," Information Systems Management, vol. 20 no. 4, pp. 43-49, 2003, DOI: 10.1201/1078/43647.20.4.20030901/77292.7.

[13] K. Hsu, J. Sylvestre, and E.N. Sayed, "Avoiding ERP Pitfalls," The Journal of Corporate Accounting \& Finance, vol. 17, no. 4, pp. 67-74, 2006, DOI: 10.1002/jcaf.20217.

[14] P. Achanga, G. Nelde, R. Roy, and E. Shehab, "Critical Success Factors for Lean Implementation within SMEs," Journal of Manufacturing Technology Management, vol. 17, no. 4, pp. 460-471, 2006, DOI: $10.1108 / 17410380610662889$

[15] S. Finney, and M. Corbett, "ERP Implementation: A Compilation and Analysis of Critical Success Factors," Business Process Management Journal, vol. 13, no. 3, pp. 329-347, 2007, DOI: $10.1108 / 14637150710752272$.

[16] F.F-H. Nah, K.M. Zuckweiler, and J.L-S. Lau, "ERP Implementation: Chief Information Officers' Perceptions of Critical Success Factors,' International Journal of Human-Computer Interaction, vol. 16, no. 1, pp. 5-22, 2003, DOI: 10.1207/S15327590IJHC1601 2.

[17] B. Snider, G.J.C. da Silveira, and J. Balakrishnan, "ERP Implementation at SMEs: Analysis of Five Canadian Cases," International Journal of Operations \& Production Management, vol. 29, no. 1, pp. 4-29, 2009, DOI: 10.1108/01443570910925343.

[18] A.Y.T. Sun, A. Yazdani, and J.D. Overend, "Achievement assessment for enterprise resource planning (ERP) system implementations based on critical success factors (CSFs)," International Journal of Production Economics, vol. 98, no. 2, pp. 189-203, 2005, DOI: 10.1016/j.ijpe.2004.05.013.

[19] C. Leyh, "Critical Success Factors for ERP System Selection, Implementation and Post-Implementation," in Readings on Enterprise Resource Planning, P.-M. Léger, R. Pellerin, and G. Babin, Eds. Montreal: ERPsim Lab, HEC Montreal, 2011, Chapter 05, pp. 63-77.

[20] J. Esteves-Sousa, and J. Pastor-Collado, "Towards the Unification of Critical Success Factors for ERP Implementations," in Proceedings of the 10th Annual Business Information Technology (BIT) Conference, Manchester, UK, 2000.

[21] K.-K. Hong, and Y.-G. Kim, "The critical success factors for ERP implementation: An organizational fit perspective," Information and Management, vol. 40, no. 1, pp. 25-40, 2002, DOI: 10.1016/S03787206(01)00134-3.

[22] T.C. Loh, and S.C.L. Koh, "Critical Elements for a Successfu Enterprise Resource Planning Implementation in Small-and MediumSized Enterprises," International Journal of Production Research, vol. 42, no. 17, pp. 3433-3455, 2004, DOI: 10.1080/00207540410001671679.

[23] H. Appelrath, and J. Ritter, SAP R/3 Implementation: Method and Tools. Berlin, Germany: Springer, 2000.

[24] M. Al-Mashari, A. Al-Mudimigh, and M. Zairi, "Enterprise resource planning: A taxonomy of critical factors," European Journal of Operational Research, vol. 146, no. 2, pp. 352-364, 2003, DOI: 10.1016/S0377-2217(02)00554-4

[25] M. Al-Mashari, and A. Al-Mudimigh, "ERP implementation: Lessons from a case study," Information Technology \& People, vol. 16, no. 1, pp. 21-33, 2003, DOI: 10.1108/09593840310463005. 
[26] F.F-H. Nah, J.L-S. Lau, and J. Kuang, "Critical factors for successful implementation of enterprise systems," Business Process Management Journal, vol. 7, no. 3, pp. 285-296, 2001, DOI: $10.1108 / 14637150110392782$.

[27] J. Becker, O. Vering, and A. Winkelmann, Softwareauswahl und einführung in Industrie und Handel - Vorgehen bei und Erfahrungen mit ERP- und Warenwirtschaftssystemen. Berlin, Germany: Springer, 2007.

[28] I. Teich, W. Kolbenschlag, and W. Reiners, Der richtige Weg zur Softwareauswahl. Berlin, Germany: Springer, 2008.

[29] J. vom Brocke, A. Simons, B. Niehaves, K. Riemer, R. Plattfaut, and A. Cleven, "Reconstructing the Giant: On the Importance of Rigour in Documenting the Literature Search Process," in Proceedings of the 17th European Conference on Information Systems (ECIS 2009), Verona, Italy, 2009.

[30] C. Leyh, "Which Factors Influence ERP Implementation Projects in Small and Medium-Sized Enterprises?," in Proceedings of the 20th
Americas Conference on Information Systems (AMCIS 2014), Savanah, Georgia, USA, 2014.

[31] F.F.-H. Nah, and S. Delgado, "Critical Success Factors for Enterprise Resource Planning Implementation and Upgrade," Journal of Computer Information Systems, vol. 46, no. 29, pp. 99-113, 2006.

[32] C. Leyh, and P. Muschick, "Critical Success Factors for ERP system Upgrades - The Case of a German large-scale Enterprise," in Proceedings of the 19th Americas Conference on Information Systems (AMCIS 2013), Chicago, USA, 2013.

[33] J. Esteves-Sousa, Definition and Analysis of Critical Success Factors for ERP Implementation Projects. Barcelona, Spain, 2004.

[34] U. Remus, "Critical Success Factors for Implementing Enterprise Portals: A Comparison with ERP Implementations," Business Process Management Journal, vol. 13, no. 4, pp. 538-552, 2007, DOI: $10.1108 / 14637150710763568$

\section{APPENDIX}

TABLE 5. OVERVIEW OF THE SMES AND INTERVIEWEES (NUMBER OF EMPLOYEES IS ROUNDED)

\begin{tabular}{|c|c|c|c|c|}
\hline Company & Industry sector & $\begin{array}{l}\text { Number of } \\
\text { employees }\end{array}$ & $\begin{array}{l}\text { Go-Live of the ERP } \\
\text { system }\end{array}$ & Interviewee \\
\hline SME 1 & Food industry & $\begin{array}{l}200 \text { in total; } 30 \text { ERP } \\
\text { system users }\end{array}$ & 2005 & Member of top management \\
\hline SME 2 & $\begin{array}{l}\text { Manufacturing of metal } \\
\text { goods / Machine-building } \\
\text { industry }\end{array}$ & $\begin{array}{l}80 \text { in total; around } 75 \\
\text { ERP system users }\end{array}$ & 2006 & $\begin{array}{l}\text { Managers of the departments } \\
\text { purchasing and service }\end{array}$ \\
\hline SME 3 & Food industry & $\begin{array}{l}40 \text { in total; } 8 \text { ERP } \\
\text { system users }\end{array}$ & 1998 & $\begin{array}{l}\text { Head of the department } \\
\text { accounting and IT }\end{array}$ \\
\hline SME 4 & Heat treatment services & $\begin{array}{l}45 \text { in total; around } 20 \\
\text { ERP system users }\end{array}$ & 2007 & Plant manager \\
\hline SME 5 & Food industry & $\begin{array}{l}110 \text { in total; around } 50 \\
\text { ERP system user }\end{array}$ & 2007 & Head of the IT department \\
\hline SME 6 & Wood / Furniture industry & $\begin{array}{l}90 \text { in total; } 55 \text { ERP } \\
\text { system users }\end{array}$ & $\begin{array}{l}\text { 2000, complete system re- } \\
\text { launch } 2005\end{array}$ & $\begin{array}{l}\text { Member of top management } \\
\text { (also manager of the IT } \\
\text { department) }\end{array}$ \\
\hline SME 7 & Automotive industry & $\begin{array}{l}80 \text { in total; } 15 \text { ERP } \\
\text { system users }\end{array}$ & 2005 & Plant manager \\
\hline SME 8 & $\begin{array}{l}\text { Manufacturing of metal } \\
\text { goods / Machine-building } \\
\text { industry }\end{array}$ & $\begin{array}{l}55 \text { in total; } 10 \text { ERP } \\
\text { system users }\end{array}$ & 2012 & $\begin{array}{l}\text { Employee of the management } \\
\text { (also member of the ERP } \\
\text { project team) }\end{array}$ \\
\hline SME 9 & Food industry & $\begin{array}{l}75 \text { in total; around } 20 \\
\text { ERP system users }\end{array}$ & $\begin{array}{l}\text { Within the end-1990s (Go- } \\
\text { Live in several steps) }\end{array}$ & Head of the IT department \\
\hline
\end{tabular}

TABLE 6. SOURCES FOR THE LITERATURE REVIEW

\begin{tabular}{|l|l|}
\multicolumn{1}{|c|}{ Databases } & \multicolumn{1}{c|}{ Conferences } \\
\hline Academic Search Complete & AMCIS \\
Business Source Complete & ECIS \\
Science Direct & HICCS \\
SpringerLink & ICIS \\
WISO & Wirtschaftsinformatik \\
\hline
\end{tabular}


TABLE 7. SEARCH FIELDS AND SEARCH TERMS

\begin{tabular}{|c|c|}
\hline Database + Search fields & Search terms / Keywords \\
\hline $\begin{array}{l}\text { Academics Search Complete: } \\
\text { "TI Title" or "AB Abstract or Author } \\
\text { Supplied Abstract" }\end{array}$ & \multirow{5}{*}{$\begin{array}{l}\text { ERP + success* } \\
\text { ERP + failure } \\
\text { ERP + crit* } \\
\text { ERP + CSF } \\
\text { ERP + CFF } \\
\text { ERP + fact* } \\
\text { "Enterprise system*" + success* } \\
\text { "Enterprise system*" + failure } \\
\text { "Enterprise system*" + crit* } \\
\text { "Enterprise system*" + CSF } \\
\text { "Enterprise system*" + CFF } \\
\text { "Enterprise system*" + fact* }\end{array}$} \\
\hline $\begin{array}{l}\text { Business Source Complete: } \\
\text { "TI Title" or "AB Abstract or Author } \\
\text { Supplied Abstract" }\end{array}$ & \\
\hline $\begin{array}{l}\text { Science Direct: } \\
\text { "Abstract, Title, Keywords" }\end{array}$ & \\
\hline $\begin{array}{l}\text { SpringerLink: } \\
\text { "Title" or "Abstract" }\end{array}$ & \\
\hline $\begin{array}{l}\text { WISO: } \\
\text { "General Search Field" }\end{array}$ & \\
\hline
\end{tabular}

